\title{
Psychiatric research in Nigeria: bridging tradition
}

\section{and modernisation}

OYEDEJI AYONRINDE, OYE GUREJE and RAHMAAN LAWAL

Nigeria is a large West African country, more than $900000 \mathrm{~km}^{2}$ in area-nearly four times the size of the UK. Despite having a population of about 117 million people, $42 \%$ of whom live in cities, Nigeria has about half the population density of the UK. About a sixth of all Africans are Nigerian. The country has a diverse ethnic mix, with over 200 spoken languages, of which three (Yoruba, Hausa and Ibo) are spoken by about $60 \%$ of the population. The official language of government and educational instruction is English. There is a federal system of government and 36 states. Religious practice has a major role in Nigeria's culture; of the two main religions, Islam predominates in the northern part of the country and Christianity in the south. A large proportion of the population still embraces traditional religions exclusively, or interwoven with either Islam or Christianity.

Although the recognition and treatment of mental disorders in Nigeria pre-date written records, Western models of psychiatric service delivery were not introduced until the early 20th century. The first asylum was established in the southern city of Calabar in 1904, and shortly afterwards (in 1907) the Yaba Asylum was established in Lagos, also in the south. These asylums were run by medical officers, as there were no psychiatrists, and provided essentially emergency and custodial interventions. In 1954, the Aro Mental Hospital was established in Abeokuta by the British colonial government in response to the need for improved mental health care (Asuni, 1967). It also provided an opportunity for the country's first indigenous psychiatrist, Dr Lambo, to spearhead service delivery on his return from the UK in 1952. The hospital, later to be known as the Aro Neuropsychiatric Hospital, was to play a central part in the development of psychiatry in Nigeria with community and World Health Organization initiatives.

\section{Current psychiatric practice}

The bulk of psychiatric service is provided by the eight regional psychiatric hospitals and the departments of psychiatry in 12 medical schools. A number of general hospitals also provide psychiatric services. Despite these facilities, mental health care remains inadequate, with the ratio of psychiatric beds being about 0.4 to 10000 persons, while that for both psychologists and social workers is 0.02 to 100000 persons (World Health Organization, 2001). As most services are in urban centres in southern parts of the country, there is both north-south and rural-urban skew in availability and accessibility of resources. Filling this void, the practice and acceptance of faith healing and traditional and complementary medicine are far-reaching in many communities. As lay views of mental illness are still rooted in supernatural belief systems and traditional illness models, orthodox psychiatric care faces the challenge of proving its efficacy in some sectors of society.

Psychiatric practice in Nigeria has been significantly influenced by its British colonial history. The majority of pioneering Nigerian psychiatrists trained in the UK in the 1960s (Jegede, 1981). Currently, most psychiatrists in the country have trained in other West African countries (encompassing Nigeria, Ghana, Liberia, Sierra Leone and The Gambia) or in national postgraduate programmes instituted in 1976 and currently run at the West African Postgraduate College and the National Postgraduate Medical College. The examinations are conducted in three stages, culminating in a supervised research project and dissertation. There are now about $\mathbf{1 1 0}$ resident doctors training in psychiatry.

\section{WORK PERFORMED AND ONGOING}

Psychiatric research in Nigeria was greatly influenced by the work of the Aro village team in Abeokuta, who pioneered community epidemiological studies among the Yoruba in collaboration with Cornell University in the USA (Leighton et al, 1963). Since then, interest has evolved in different aspects of psychiatric disorders and services. The current scope of research in Nigeria ranges from descriptive studies to large, multicentre epidemiological research projects. Research also spans social science and neurobiology. Despite the dearth of resources, a number of significant contributions have been made to both international and local psychiatric research literature.

\section{Schizophrenia}

Nigeria was one of the key centres for the landmark International Pilot Study of Schizophrenia (IPSS), the ten-country study of the incidence and manifestations of schizophrenia. An important outcome was the better prognosis in Nigeria and other less developed countries. Recent research includes studies in neuroimaging, longitudinal social outcome, caregiver burden (Ohaeri, 2001) and cost of treatment (Suleiman et al, 1997), to mention a few.

\section{Primary care}

The majority of psychiatric presentations seen by clinicians are in primary care. A number of studies have assessed psychological symptoms and morbidity in both rural and urban primary care settings (Abiodun, 1993; Gureje, 2002). In the World Health Organization (WHO) 14country study of psychological problems in general health care (Simon \& Gureje, 1999), prevalence, course and prognostic factors influencing somatisation and painrelated disorders were investigated in Ibadan, contributing to cross-national awareness of these disorders.

\section{Dementia}

One of the current areas of research in Nigeria is the collaborative study of dementia by researchers at the University of Ibadan and the University of Indiana in the USA. This longitudinal study has been going on for over a decade, and among its major findings is the observation that both the prevalence and incidence of Alzheimer's disease are significantly less among the Yoruba in Nigeria than among African Americans living in Indianapolis (Hendrie et al, 2001). This project is currently in 
the phase of exploring putative genetic and environmental factors that may underlie this difference, including the role of apolipoprotein E. The work of this team is possibly the most cited current research from Nigeria.

\section{Substance misuse}

Substance misuse research is a rapidly evolving field reflecting changing patterns of drug use in Nigeria. Areas of research focus include the identification of user groups, their patterns of use, risk and harm minimisation, as well as the development of culturally acceptable treatment interventions. The research team at the drug rehabilitation unit of the psychiatric hospital in Yaba, Lagos, has been at the forefront of some of the most current investigations. A WHO-sponsored evaluation of injecting drug use in Lagos (further details available from R.L. on request) highlighted the hitherto uncommon practice of this type of drug use among cocaine and heroin users in cosmopolitan Lagos. Non-sterile practice was not uncommon among these users, as well as unprotected sexual activity with poor awareness of blood-borne viruses. These findings have major policy implications, as the current emphasis on supply control and demand reduction without systematic harm reduction practices is inadequate. Research in this area also has far-reaching public health implications through shedding light on the impact of previously unfamiliar Western forms of substance misuse in Nigeria. Health service research involving the evaluation of therapeutic interventions such as detoxification, group therapy sessions, occupational and vocational rehabilitation and relapse prevention initiatives is also in the process of dissemination.

\section{Traditional healing}

As the bulk (approximately 70\%) of mental health service provision is delivered through non-orthodox means such as religious organisations and traditional healers, research into these services and their implications for psychiatry is important. A number of centres have assessed the role of traditional therapists in mental health interventions (Adelekan et al, 2001). A common finding was that traditional healers could recognise symptoms of severe mental illness, but that they expressed strong belief in supernatural factors as a cause of mental illness. Psychoeducation was found to improve their understanding of aetiology and to reduce their tendency to use corporeal interventions. There remain numerous opportunities to work closely with healers, who may be the first point of contact in some communities.

\section{Psychopharmacology}

Psychopharmacological research in Nigeria is limited by restricted pharmaceutical industry funding of trials and the unsubsidised cost of psychotropic medication. A recent open-label study of risperidone in the treatment of schizophrenia carried out in Lagos and Kaduna observed a notable decline in total Positive and Negative Syndrome Scale scores, extrapyramidal side-effects and improved social functioning. Findings were generally similar to those reported from other countries in this multicentre trial (Lawal et al, 2003). The lack of significant subsidies for such medication prohibits its use beyond trial periods for many. Studies like these are all the more pertinent in a period of international concern about the dearth of drug trials across geographical, racial and ethnic groups.

\section{NEW INITIATIVES \\ AND CHALLENGES FOR THE FUTURE}

Psychiatric research output in Nigeria reflects the paradox of a paucity of specialists in the field but a high academic research output by the few. A Medline survey of publications on different psychiatric disorders and treatments in Nigeria over the past 50 years identified modest numbers but diverse interests in areas such as schizophrenia (98), depression (80), bipolar affective disorder (23), dementia (44), suicide (25), electroconvulsive therapy (12), substance misuse (120), antidepressants (8), antipsychotics (21), forensic psychiatry (18), somatisation (10) and psychotherapies (42). Although this list is far from exhaustive, it reflects the evolution of academic psychiatry in Nigeria. Most of this research consists of small-scale surveys and descriptive clinical studies of psychological morbidity in different groups, as well as phenomenological studies. Intervention studies are few, as are cohort studies. Research into childhood and old age mental health issues is very much in its infancy. The bulk of research in Nigeria has not been disseminated internationally, although a number of studies have been published in major journals, most are to be found in national, regional and African publications, much of which may be unavailable to a wider international audience. Given the linguistic and cultural diversity of Nigeria, significant effort is required in the preparation and standardisation of culturally sensitive and specific research tools (Gureje, 1991; Uwakwe, 2003). Furthermore, health models and treatment options vary nationally, limiting the generalisability of research findings (Ayonrinde, 2003).

After completion of training, postgraduate residents are encouraged to publish their research; however, there are few incentives to do so. With limited research funding opportunities, less established researchers are often unable to attend international meetings or network with experts. Although use of the internet has facilitated access to journal abstracts, few libraries stock a wide enough range of psychiatric journals, given the exorbitant institutional subscription fees. ${ }^{1}$ Scientific bodies, publishers, funding bodies, clinicians and academics around the world may be able to provide a solution to this problem.

\section{CONCLUSIONS}

Mental health research in Nigeria is rich in untapped opportunities, such as the highest twin rate in the world among the Yoruba. In our opinion, international collaboration is a key to advancing psychiatric research in Nigeria through skill development and resource sharing.

\section{REFERENCES}

Abiodun, O. A. (1993) A study of mental morbidity among primary care patients in Nigeria. Comprehensive Psychiatry, 34, 10-13.

Adelekan, M. L., Makanjuola, A. B. \& Ndom, R. J. (200I) Traditional mental health practitioners in Kwara State, Nigeria. East African Medical Journal, 78, 190-196.

Asuni, T. (1967) Aro Mental Hospital in perspective. American Journal of Psychiatry, 124, 763-770.

I. The Royal College of Psychiatrists makes available the online versions of the British Journal of Psychiatry, Psychiatric Bulletin and Advances in Psychiatric Treatment free of charge to 75 of the world's poorest countries, including Nigeria. For further information, see http: / /www. rcpsych.ac.uk/publications/dev_countries. htm. 
Ayonrinde, O. A. (2003) Importance of cultura sensitivity in therapeutic transactions: considerations for healthcare providers. Disease Management and Health Outcomes, II, 233-248.

Gureje, $\mathbf{O}$. (1991) Reliability and the factor structure of the Yoruba version of the 12-item General Health Questionnaire. Acta Psychiatrica Scandinavica, 84, 125-129.

Gureje, O. (2002) Psychological disorders and symptoms in primary care: association with disability and service use after 12 months. Social Psychiatry and Psychiatric Epidemiology, 37, 220-224.

Hendrie, H. C., Ogunniyi, A., Hall, K. S., et al (2001) Incidence of dementia and Alzheimer disease in 2 communities: Yoruba residing in Ibadan, Nigeria, and African Americans residing in Indianapolis, Indiana. JAMA, 285, 739-747.

Jegede, R. O. (198I) Nigerian psychiatry in perspective. Acta Psychiatrica Scandinavica, 63, 45-56.

Lawal, R. A., Suleiman, G. T. \& Onyenze, B. (2003) Risperidone in the treatment of schizophrenia. Nigerian Medical Practitioner, 44, II-18.

OYEDEJI AYONRINDE, MBBS, MRCPsych, MSc, South London and Maudsley NHS Trust, London, UK; OYE GUREJE, MBBS, PhD, FRCPsych, University of Ibadan, Nigeria; RAHMAAN LAWAL, MBBS, FMCPsych, $\mathrm{MPH}$, Drug Rehabilitation Unit, Psychiatric Hospital, Yaba, Lagos, Nigeria

Correspondence: Dr O. Ayonrinde, Consultant Psychiatrist, Bethlem Royal Hospital, Beckenham BR3 3BX, UK. E-mail: deji.ayonrinde@slam.nhs.uk

Leighton, A. H., Lambo, T. A., Hughes, C. C., et al (1963) Psychiatric Disorder Among the Yoruba - A Repor from the Cornell-Aro Mental Health Research Project in the Western Region, Nigeria. Ithaca, NY: Cornell University Press.

Ohaeri, J. U. (200I) Caregiver burden and psychotic patients' perception of social support in a Nigerian setting. Social Psychiatry and Psychiatric Epidemiology, 36, 86-93.

Simon, G. E. \& Gureje, O. (1999) Stability of somatization disorder and somatization symptoms among patients in primary care. Archives of General Psychiatry, 56, 90-95.
Suleiman, T. G., Ohaeri, J. U., Lawal, R. A., et al (1997) Financial cost of treating out-patients with schizophrenia in Nigeria. British Journal of Psychiatry, I7I, 364-368.

Uwakwe, R. (2003) Affective (depressive) morbidity in puerperal Nigerian women: validation of the Edinburgh Postnatal Depression Scale. Acta Psychiatrica Scandinavica, 107, 251-259.

World Health Organization (2001) Atlas: Country Profiles on Mental Health Resources. Geneva: WHO. 